\title{
Deregulated microRNAs in gastric cancer tissue-derived mesenchymal stem cells: novel biomarkers and a mechanism for gastric cancer
}

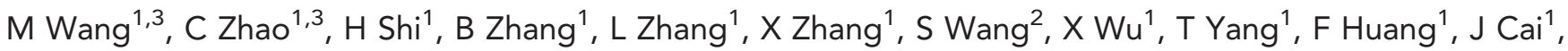 \\ Q Zhu ${ }^{1}, \mathrm{~W} \mathrm{Zhu}^{1}, \mathrm{H}$ Qian ${ }^{*, 1}$ and W Xu ${ }^{*, 1}$ \\ ${ }^{1}$ School of Medical Science and Laboratory Medicine, Jiangsu University, Zhenjiang 212013, Jiangsu, China and ${ }^{2}$ Department of \\ Surgery, The First People's Hospital of Zhenjiang, Zhenjiang 212001, Jiangsu, China
}

Background: MicroRNAs (miRNAs) are involved in gastric cancer development and progression. However, the expression and role of miRNAs in gastric cancer stromal cells are still unclear.

Methods: The miRNAs differentially expressed in gastric cancer tissue-derived mesenchymal stem cells (GC-MSCs) relative to adjacent non-cancerous tissue-derived MSCs (GCN-MSCs) and in cancer tissues relative to adjacent non-cancerous tissues were screened using miRNA microarray and validated by quantitative RT-PCR. The impact of GC-MSCs on HGC-27 cells was observed in vitro using colony formation and transwell assays, and these cells were subcutaneously co-injected into mice to assess tumour growth in vivo. Exogenous downregulation of miR-221 expression in cells was achieved using an miRNA inhibitor.

Results: miR-214, miR-221 and miR-222 were found to be commonly upregulated in GC-MSCs and cancer tissues. Their levels were tightly associated with lymph node metastasis, venous invasion and the TNM stage. Gastric cancer tissue-derived mesenchymal stem cells significantly promoted HGC-27 growth and migration and increased the expression of miR-221 via paracrine secretion, and the targeted inhibition of miR-221 in GC-MSCs could block its tumour-supporting role. GC-MSC-derived exosomes were found to deliver miR-221 to HGC-27 cells and promoted their proliferation and migration.

Conclusions: Gastric cancer tissue-derived mesenchymal stem cells favour gastric cancer progression by transferring exosomal miRNAs to gastric cancer cells, thus providing a novel mechanism for the role of GC-MSCs and new biomarkers for gastric cancer.

Gastric cancer is the second most common human malignant disease and the third most frequent cause of cancer-related death in developing countries (Jemal et al, 2011). Although the outcomes of gastric cancer patients have been notably improved by standardised surgical treatment and better perioperative care (Ding et al, 2012), the diagnosis of gastric cancer at early stages remains a challenge in clinical settings.
MicroRNAs (miRNAs), an abundant class of 19-25-nt noncoding RNAs with important regulatory functions in diverse biological processes, have been demonstrated to be ideal biomarkers and therapeutic intervention targets (Ciesla et al, 2011). MiRNAs are involved in carcinogenesis and cancer progression as oncogenes or tumour suppressors (Calin and Croce, 2006). A number of studies have investigated the diagnostic and

\footnotetext{
*Correspondence: Professor H Qian; E-mail: Istmmlst@163.com or Professor W Xu; E-mail: icls@ujs.edu.cn
}

${ }^{3}$ These authors contributed equally to this work.

Received 30 September 2013; revised 9 December 2013; accepted 23 December 2013; published online 28 January 2014 
prognostic values of miRNAs in gastric cancer (Li et al, 2010; Ueda et al, 2010). Aberrant miRNAs have been tested in clinical settings as diagnostic biomarkers in biopsy specimens and bodily fluids (Liu et al, 2011; Tsujiura et al, 2010). Most of the previous studies have focused on the differentially expressed miRNAs in cancer tissues and cells. However, the miRNAs in tumour stromal cells are still unclear.

The notion that the biology of cancer can no longer be understood simply by enumerating the traits of the cancer cells but, instead, must encompass the contributions of the 'tumour microenvironment' to carcinogenesis has been solidified and extended (Hanahan and Weinberg, 2011). The position of cancer-associated stromal cells, which are important components of the tumour microenvironment, in directing tumour progression has been established (Hanahan and Coussens, 2012; Horimoto et al, 2012; Fang and Declerck, 2013). Accumulating evidence has demonstrated that interactions between bone marrow-derived mesenchymal stem cells (BM-MSCs) and cancer cells endow the latter with proliferative, invasive and metastatic properties (Karnoub et al, 2007; Roorda et al, 2009; Bergfeld and DeClerck, 2010; Yang et al, 2013).

Recently, exosomes have been intensively studied in carcinomas. Exosomes are small RNA- and protein-containing extracellular vesicles that are thought to mediate cross-talk between stromal cells and cancer cells (Azmi et al, 2013). Tumour-derived exosomes are believed to promote reprogramming of the tumour-associated stroma to favour tumour growth and metastasis (Webber et al, 2010; Cho et al, 2011, 2012; Gu et al, 2012). Recently, several studies have revealed that exosomal miRNAs that are secreted by stromal cells affect the biological behaviour of cancer cells (Kahlert and Kalluri, 2013; Roccaro et al, 2013). However, little is known about the existence and possible role of such miRNAs in gastric cancer.

In our previous studies, we successfully isolated mesenchymal stem cells from the gastric cancer tissues (GC-MSCs) and their adjacent non-cancerous tissues (GCN-MSCs) (Cao et al, 2009; $\mathrm{Xu}$ et al, 2011). We demonstrated that GC-MSCs and GCN-MSCs share most of the properties of BM-MSCs but have some differences in surface marker expression, proliferation, migration and gene profiles ( $\mathrm{Xu}$ et al, 2011). To better understand the role of MSCs in gastric cancer, in this study, we screened for differentially expressed miRNAs in GC-MSCs relative to GCN-MSCs, determined the role of these miRNAs in gastric cancer and evaluated their potential as biomarkers. We identified miR-214, miR-221 and miR-222 as commonly upregulated miRNAs in GC-MSCs and gastric cancer tissues and further revealed that these miRNAs were critical for the promotion of gastric cancer growth in vitro and in vivo by MSCs.

\section{MATERIALS AND METHODS}

Clinical samples. All of the studies were approved by the Ethics Committee of Jiangsu University (2012258), and informed consent was obtained from all subjects. Sixty-five gastric cancer tissues and adjacent non-cancerous gastric tissues were obtained from patients undergoing surgical resection. The patients had not undergone any previous treatment before the operation. The clinical specimens were collected between July 2009 and June 2012 at the Department of Surgery at the Affiliated People's Hospital of Jiangsu University, China, and the gastric cancer tissues and adjacent non-cancerous tissues were histologically confirmed. For cell isolation, gastric cancer tissues and the corresponding grossly non-cancerous gastric tissues (at least $5 \mathrm{~cm}$ away from the cancer tissues) were harvested within $30 \mathrm{~min}$ after resection and maintained in Dulbecco's modified Eagle medium (DMEM, Invitrogen, Carlsbad, CA, USA) with $10 \%$ fetal bovine serum (FBS, Invitrogen) and penicillinstreptomycin on ice for immediate transportation to the laboratory. The remaining tissue samples were immediately stored at $-80^{\circ} \mathrm{C}$ until use.

Cell culture. The procedure for GC-MSC, GCN-MSC and BM-MSC isolation has been described previously (Cao et al, 2009; Xu et al, 2011). For GC-MSC and GCN-MSC isolation, fresh tissues were washed with phosphate-buffered saline (PBS), cut into $1-\mathrm{mm}^{3}$-sized pieces and floated in DMEM with low glucose (LG-DMEM) (Invitrogen) containing 10\% FBS, penicillin and streptomycin. The tissue pieces were subsequently incubated at $37^{\circ} \mathrm{C}$ in humid air with $5 \% \mathrm{CO}_{2}$, and the medium was replaced every 3 days after the initial plating. When adherent fibroblast-like cells appeared after 10 days of culture, the cells were trypsinised and passaged into a new flask for further expansion. Human gastric cancer HGC-27 cells were obtained from the China Academia Sinica Cell Repository, Shanghai, China, and were maintained in DMEM with high glucose (HG-DMEM) (Invitrogen) containing $10 \% \mathrm{FBS}$ and incubated at $37^{\circ} \mathrm{C}$ in humid air with $5 \% \mathrm{CO}_{2}$.

MiRNA microarray analysis. The microarray analysis for miRNA profiling was conducted by the Shanghai Kangcheng Technology using the miRCURY LNA Array system (Exiqon, Vedbaek, Denmark). Total RNA was extracted and purified using the mirVana miRNA Isolation Kit (Ambion, Austin, TX, USA) following the manufacturer's instructions. Each array was hybridised with $100 \mathrm{ng}$ of Cy3-labelled RNA using the miRNA Complete Labeling and Hyb Kit (Exiqon) in a hybridisation oven that was set at $55^{\circ} \mathrm{C}$ and 20 r.p.m. for $20 \mathrm{~h}$ according to the manufacturer's instructions. After hybridisation, each array was washed in staining dishes with the Gene Expression Wash Buffer and scanned, and the raw data were normalised using the quantile algorithm. The threshold value for significance that was used to define upregulation or downregulation of miRNAs was a fold change $>2$ or $<0.5$, respectively.

RNA isolation and quantitative RT-PCR assay. Total RNA from the tissues and cells was isolated using TRIzol Reagent (Invitrogen). Exosomal and serum miRNAs were extracted from $400 \mu \mathrm{l}$ of serum by using the miRNeasy Mini Kit (Qiagen, Hilden, Germany) and reversely transcribed using the miScript II RT Kit (Qiagen). Quantitative RT-PCR (qRT-PCR) assays were performed using the miScript SYBR Green PCR Kit (Qiagen) and the Bio-Rad fluorescence thermal cycler (Bio-Rad Laboratories, lnc., Hercules, CA, USA) for quantitative miRNA detection. The relative expression levels of the miRNAs in tissue and cells were normalised to U6 and those in the serum and exosomes were normalised to the insert control according to the manufacturer's protocol.

Colony formation assay. Soft agar colony formation: MSCs were seeded at a density of $5 \times 10^{3}$ in six-well plates (Corning Incorporated, Corning, NY, USA) and incubated for $12 \mathrm{~h}$. Then, base agar layers were prepared by placing $1.5 \mathrm{ml}$ of a $2 \times$ LGDMEM $20 \%$ FBS and $1.2 \%$ sterile agar $(1: 1)$ mixture into the six-well dishes and the agar was allowed to form for $1 \mathrm{~h}$ at room temperature. HGC-27 cells were then trypsinised and resuspended at a concentration of 4000 cells per $1 \mathrm{ml} 2 \times$ HG-DMEM with $20 \%$ FBS and mixed with $0.6 \%$ sterile agar $(1: 1)$. Two millilitres of the cell suspension was added to the agar plates and then incubated for 15 days. The colonies in the top agar layer were counted using a dissecting microscope (magnification, $\times 40$ ). Experiments were performed in triplicate, and 10 fields were counted for each experiment. Plate colony formation: HGC-27 cells were treated with exosomes for $48 \mathrm{~h}$, trypsinised, resuspended at a concentration of 1000 cells per $2 \mathrm{ml} \mathrm{HG-DMEM}$ with 10\% FBS and then incubated for 10 days. Colonies were fixed with methanol, stained with crystal violet and counted. 
Transwell migration assay. To assay the effect of GC-MSCs on HGC-27 migration, $2 \times 10^{4}$ of MSCs were plated in the lower chamber and $1 \times 10^{5}$ of HGC-27 cells were plated in the top chamber of transwell plates ( $8-\mu \mathrm{m}$ pore size, Corning). To assay the effect of GC-MSC-derived exosomes on HGC-27 migration, HG-DMEM with $10 \%$ FBS was plated in the lower chamber and $2 \times 10^{5}$ exosome-treated HGC-27 cells were plated in the top chamber of transwell plates. The top-chamber cells were incubated for $10 \mathrm{~h}$, and cells that did not migrate through the pores were removed with a cotton swab. Cells on the lower surface of the membrane were fixed with methanol and stained with crystal violet. The migration ability of the cells was determined by counting the cells using a microscope (magnification, $\times 100$ ). Experiments were performed in triplicate, and at least six fields were counted for each assay.

Synthesis and transfection of the miRNA inhibitor. The miR221 inhibitor (anti-miR-221) and negative control (NC) oligonucleotides were synthesised and purified by RiboBio (RiboBio Co., Ltd, Guangzhou, China). GC-MSCs or HGC-27 cells were seeded in sixwell plates (Corning) at 40-60\% confluence and cultured overnight. Transfection was performed using Lipofectamine 2000 (Invitrogen), and the concentration of anti-miR-221 and NC was $100 \mathrm{~nm}$.

Animal studies. Four- to five-week-old BALB/c nude mice were purchased from the Slac Laboratory Animal Centre (Shanghai, China). The animals were maintained in accordance with institutional policies, and all studies were performed with approval of the University Committee on Use and Care of Animals of Jiangsu University. Of HGC-27 cells $\left(1 \times 10^{6}\right)$ and MSCs $\left(3 \times 10^{5}\right)$ were trypsinised, washed and resuspended in $100 \mu \mathrm{l} \mathrm{PBS}$. Then, the cells were mixed and co-injected into the left flanks of the nude mice. Tumour size was assessed every 3 days by caliper measurement, and tumour volume was calculated based on the modified ellipsoid formula $(L \times W \times W / 2)$, where $L$ represents length and $W$ represents width. Tumours were surgically removed 22 days after injection and serum was collected from the same mice 1 day before surgery.

Isolation and characterisation of exosomes. GC-MSCs and GCN-MSCs were cultured in a serum-free medium. Supernatant fractions that were collected from 48-h MSC cultures were filtered using $0.22-\mu \mathrm{m}$ pore filters, as previously described (Valadi et al, 2007), followed by ultracentrifugation at $20000 \mathrm{~g}$ for $20 \mathrm{~min}$ and incubation with an ExoQuick exosome precipitation solution
(SBI System Biosciences, Mountain View, CA, USA). Exosomes were then harvested by ultracentrifugation at $100000 \mathrm{~g}$ for $30 \mathrm{~min}$ according to the manufacturer's specification. Final exosomes were obtained and stored at $-70^{\circ} \mathrm{C}$, and the morphology of the collected exosomes was observed by transmission electron microscopy (FEI Tecnai 12, Philips, Eindhoven, The Netherlands). The CD63 (Bioworld Technology, Inc., Minneapolis, MN, USA), which is frequently located on the surface of exosomes, was analysed using western blotting.

Exosome labelling, internalisation and immunofluorescent staining. MSC-derived exosomes were labelled with CM-Dil (red) according to the manufacturer's protocol (Invitrogen). The labelled exosome suspension was filtered using a 100-kDa MWCO hollow fibre membrane (Millipore Corporation, Billerica, MA, USA), and the flow-through was used as the unbound dye control. HGC-27 cells were seeded in 12-well plates containing lamellas and incubated at $37^{\circ} \mathrm{C}$ with the labelled exosomes $\left(100 \mu \mathrm{g} \mathrm{ml}^{-1}\right)$ for $4 \mathrm{~h}$ before harvesting. The HGC-27 cells were fixed in $4 \%$ paraformaldehyde for $10 \mathrm{~min}$, and the labelled cells were prepared for fluorescence microscopy by permeabilisation for $3 \mathrm{~min}$ with $0.1 \%$ Triton X-100, blocking with 5\% BSA and incubation with a rabbit monoclonal anti- $\beta$-actin antibody (Santa Cruz Biotechnology, Inc., Dallas, TX, USA) overnight, which was followed by incubation with a Cy2-labelled anti-rabbit IgG (green) secondary antibody (Jackson ImmunoResearch Laboratories, Inc., West Grove, PA, USA) at $37^{\circ} \mathrm{C}$ for $45 \mathrm{~min}$. The nuclei were counterstained with DAPI (blue). Confocal images were sequentially acquired using the TCS SP5 II system (Leica, Wetzlar, Germany).

Statistical analysis. Statistical analysis was performed using the PASW Statistics 18 software (SPSS Inc., Chicago, IL, USA). Data are presented as the mean or mean \pm s.d. Differences in the miRNA levels of the tissues were analysed using the Wilcoxon signed-rank test. Possible differences between different treatment groups were analysed using one-way ANOVA, paired $t$-test and $\chi^{2}$-test. A probability level of 0.05 was chosen for statistical significance.

\section{RESULTS}

MiRNA microarray screening for common deregulated miRNAs in GC-MSCs and gastric cancer tissues. Paired GC-MSCs and GCN-MSCs were isolated from three gastric cancer patients.
A
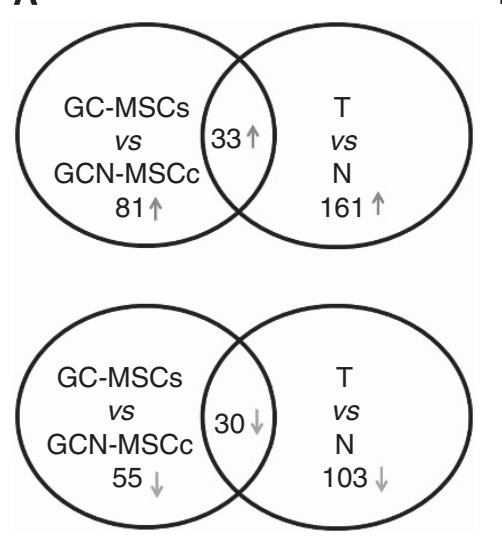
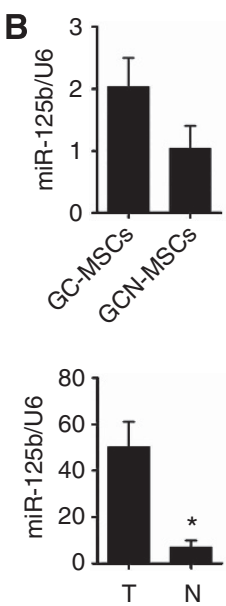
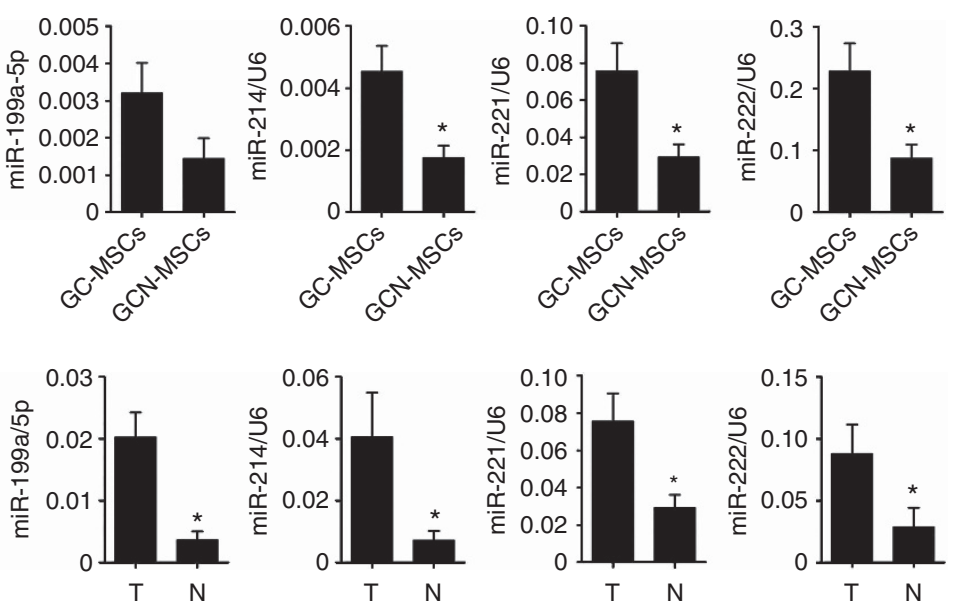

Figure 1. MicroRNAs that are deregulated in GC-MSCs and gastric cancer tissues. (A) Microarray analysis of the aberrant expression of miRNAs in GC-MSCs relative to that in GCN-MSCs and in gastric cancer tissues (T) relative to adjacent non-cancerous gastric tissues (N). Venn diagrams of the miRNAs that were upregulated $(\uparrow)$ and downregulated $(\downarrow)$ in GC-MSCs and gastric cancer tissues are shown. (B) The relative levels of the selected miRNAs (miR-125b, miR-199a-5p, miR-214, miR-221 and miR-222) in GC-MSCs and gastric cancer tissues from 10 patients were confirmed using qRT-PCR. The levels of these miRNAs were normalised to that of U6. The data are presented as mean \pm s.d., ${ }^{\star} P<0.05$. 
We used an Exiqon miRCURY LNA Array to evaluate the differentially expressed miRNAs in GC-MSCs relative to GCNMSCs and in gastric cancer tissues (T) relative to non-cancerous gastric tissues $(\mathrm{N})$. After quartile normalisation, we identified 114 upregulated (fold change $>2$ ) and 85 downregulated (fold change $<0.5$ ) miRNAs in GC-MSCs. The tissue miRNA profile showed 194 upregulated (fold change $>2$ ) and 133 downregulated (fold change $<0.5)$ miRNAs in gastric cancer tissues. We compared the miRNA profiles between two groups and found 33 upregulated and 30 downregulated miRNAs in the GC-MSCs and gastric cancer tissue groups (Figure 1A; Table 1).

Validation of the overlapped miRNAs that were deregulated in GC-MSCs and gastric cancer tissues. To validate the miRNA microarray results, five of these overlapping upregulated miRNAs, including miR-125b, miR-199a-5p, miR-214, miR-221 and miR-222, in 10 pairs of GC-MSCs and GCN-MSCs and the matched gastric cancer tissues $(\mathrm{T})$ and non-cancerous gastric tissues (N) were selected for qRT-PCR analysis. The results showed that the levels of miR-214, miR-221 and miR-222 were significantly higher in GC-MSCs and gastric cancer tissues than in paired GCN-MSCs and non-cancerous gastric tissues (Figure 1B). The other two miRNAs, miR-125b and miR-199a-5p, were expressed at higher levels only in gastric cancer tissues and not in their paired GC-MSCs (Figure 1B). Therefore, miR-214, miR-221 and miR-222 were designated as GG-miRNAs and further analysed in subsequent studies.

Clinical significance of GG-miRNAs in gastric cancer. To determine the clinical relevance of GG-miRNAs in gastric cancer,

Table 1. The dysregulated miRNAs overlapping in GC-MSC and gastric cancer tissues

Fold change

Fold change

\begin{tabular}{|c|c|c|c|c|c|}
\hline Upregulated miRNA & GC-MSC vs GCN-MSC & GC vs normal & Downregulated miRNA & GC-MSC vs GCN-MSC & GC vs normal \\
\hline ebv-miR-BART7* & 5.92512274 & 3.434888 & hsa-miR-1228 & 0.447454474 & 0.169486848 \\
\hline ebv-miR-BART9* & 3.16829316 & 2.926985 & hsa-miR-1237 & 0.099958173 & 0.15362951 \\
\hline hsa-let-7b* & 10.7275498 & 4.897288 & hsa-miR-124* & 0.486205219 & 0.328964128 \\
\hline hsa-miR-125b & 171.074862 & 13.97903 & hsa-miR-1247 & 0.338720281 & 0.170704403 \\
\hline hsa-miR-127-3p & 48.413193 & 4.081004 & hsa-miR-1249 & 0.271433226 & 0.160842976 \\
\hline hsa-miR-1290 & 9.16273439 & 3.262979 & hsa-miR-1291 & 0.20993624 & 0.351896503 \\
\hline hsa-miR-1308 & 15.3220282 & 3.322310 & hsa-miR-133b & 0.307780245 & 0.382595144 \\
\hline hsa-miR-138-1* & 3.57023503 & 3.380641 & hsa-miR-183* & 0.106162554 & 0.320880934 \\
\hline hsa-miR-140-3p & 18.2010693 & 4.065812 & hsa-miR-18b* & 0.334036304 & 0.141184779 \\
\hline hsa-miR-181a & 52.3463463 & 5.798735 & hsa-miR-205 & 0.283584937 & 0.387797802 \\
\hline hsa-miR-195* & 7.91515358 & 2.052396 & hsa-miR-296-5p & 0.385850207 & 0.202224228 \\
\hline hsa-miR-199a-5p & 152.428412 & 8.502778 & hsa-miR-302c* & 0.10914993 & 0.28354334 \\
\hline hsa-miR-203 & 9.15452237 & 3.917800 & hsa-miR-324-3p & 0.421655332 & 0.191952018 \\
\hline hsa-miR-21* & 165.619783 & 3.165780 & hsa-miR-484 & 0.480162737 & 0.420454854 \\
\hline hsa-miR-214 & 7.05311859 & 7.130019 & hsa-miR-508-5p & 0.396964046 & 0.290524222 \\
\hline hsa-miR-221 & 81.2037893 & 5.466395 & hsa-miR-516a-3p & 0.336522216 & 0.385213215 \\
\hline hsa-miR-222 & 113.493453 & 2.877310 & hsa-miR-518b & 0.455208342 & 0.402421473 \\
\hline hsa-miR-23a & 9.42514935 & 14.12156 & hsa-miR-518e* & 0.305406211 & 0.345724839 \\
\hline hsa-miR-23b & 2.19275711 & 13.43332 & hsa-miR-519e* & 0.456420331 & 0.420809458 \\
\hline hsa-miR-24-2* & 20.7215506 & 2.187237 & hsa-miR-557 & 0.404778204 & 0.352643889 \\
\hline hsa-miR-302e & 3.17971329 & 2.015585 & hsa-miR-611 & 0.281290232 & 0.150331309 \\
\hline hsa-miR-30a & 5.25418283 & 2.158002 & hsa-miR-615-5p & 0.216754867 & 0.159182766 \\
\hline hsa-miR-32* & 41.8790997 & 4.842259 & hsa-miR-623 & 0.314603355 & 0.464909663 \\
\hline hsa-miR-335 & 2.43061729 & 18.54524 & hsa-miR-659 & 0.460354656 & 0.288467401 \\
\hline hsa-miR-338-5p & 2.28544381 & 2.892081 & hsa-miR-664 & 0.478842823 & 0.24658777 \\
\hline hsa-miR-491-3p & 40.8897475 & 3.090251 & hsa-miR-675 & 0.218125011 & 0.276206099 \\
\hline hsa-miR-550 & 4.91148632 & 2.072431 & hsa-miR-720 & 0.290653253 & 0.341231054 \\
\hline hsa-miR-574-3p & 4.39453468 & 3.777058 & hsa-miR-877* & 0.294194473 & 0.295195107 \\
\hline hsa-miR-574-5p & 11.2838171 & 5.024267 & hsa-miR-936 & 0.323719523 & 0.44197424 \\
\hline hsa-miR-576-3p & 3.82795738 & 2.819507 & hsa-miR-940 & 0.429724991 & 0.179586907 \\
\hline hsa-miR-645 & 2.47820572 & 3.349002 & & & \\
\hline hsa-miR-886-3p & 138.577867 & 10.01466 & & & \\
\hline hsa-miR-886-5p & 6.86889819 & 11.47979 & & & \\
\hline
\end{tabular}



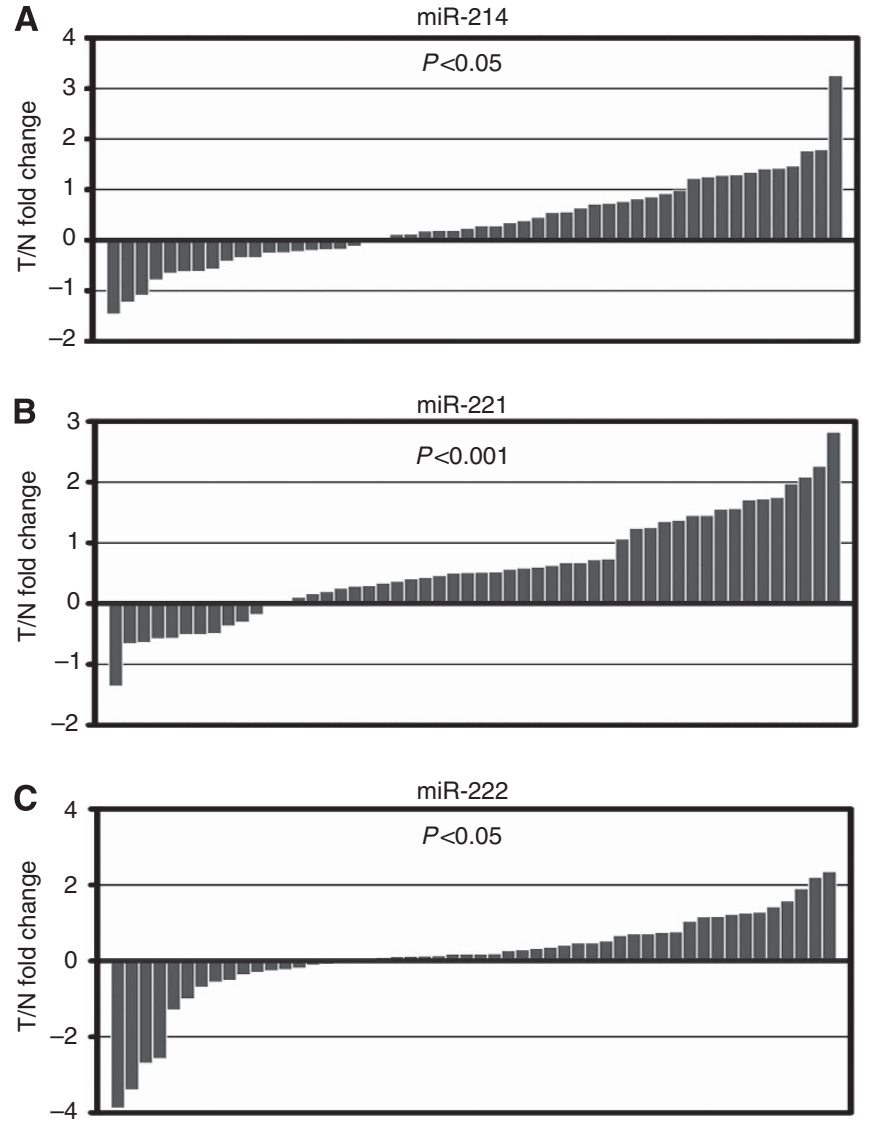

Figure 2. Expression of GG-miRNAs in gastric cancer tissues.

(A) miR-214, (B) miR-221 and (C) miR-222 levels (normalised to U6) were determined using QRT-PCR in gastric cancer tissues (T) relative to adjacent non-cancerous tissues (N) from 52 gastric cancer patients. Each column represents the T/N miRNA fold change. The data are presented as the mean. The $P$-value denotes the significance of the observed fold changes.

we measured the expression of miR-214, miR-221 and miR-222 in another cohort of 52 gastric cancer tissues (T) and matched noncancerous gastric tissues (N) using qRT-PCR. The results showed that miR-214, miR-221 and miR-222 were upregulated in gastric cancer tissues compared with non-cancerous gastric tissues (Figure 2). These gastric cancer patients were categorised into groups of high and low levels of GG-miRNAs according to the median level of each GG-miRNA. The relationship between GG-miRNA levels and clinicopathological features were analysed (Table 2). The miR-221 and miR-222 high-expression group showed more extensive lymph node metastasis than the lowexpression group. The miR-214 and miR-222 high-expression group had inclinations of more serosal invasion than the lowexpression group. In addition, the levels of miR-214, miR-221 and miR-222 were positively correlated with the TNM stage. The results also showed that high levels of miR-214 were correlated with venous invasion. However, no correlations between the GG-miRNA level and other clinical features, such as age, sex or cancer type, were observed.

GC-MSCs promote cell proliferation, migration and GGmiRNA expression in gastric cancer cells in vitro. GC-MSCs are a type of stromal cell for gastric cancer, but their role in gastric cancer progression is still unknown. We performed a soft agar colony formation assay to determine the effect of MSCs on the colony-forming ability of gastric cancer cells in vitro. GC-MSCs, GCN-MSCs and BM-MSCs were plated on the bottom of the wells as the feed cells. The results showed that HGC-27 cells grown on MSCs formed more colonies than the HGC-27-alone group (Figure 3A). Similar results were also observed for SGC-7901 gastric cancer cells (data not shown). We also performed a transwell migration assay to evaluate the effect of MSCs on the migratory ability of HGC-27 cells. As shown in Figure 3B, MSCs significantly induced HGC-27 cells to migrate, and the number of migrated HGC-27 cells in the GC-MSC group was $\sim 1.5$-fold higher than that of the other groups.

To determine whether GG-miRNA levels in gastric cancer cells are affected by GC-MSCs, we cultured HGC-27 cells in a conditioned medium (CM) from GC-MSCs, GCN-MSCs and BM-MSCs for 3 weeks. The cells were harvested, and the levels of miR-214, miR-221 and miR-222 were measured using qRT-PCR. The data showed that HGC-27 cells grown in GC-MSC-CM expressed the highest levels of miR-221 and miR-222 among all the groups. The miR-214 level in the GC-MSC-CM group was similar to that of the BM-MSC-CM group but higher than that of the GCN-MSC-CM and HGC-27 groups (Figure 3C). These observations suggest that GC-MSCs promote the proliferation and migration of gastric cancer cells and induce the expression of GG-miRNAs in gastric cancer cells.

GC-MSCs promote gastric cancer cell growth and GG-miRNA expression in vivo. To further investigate the role of GC-MSCs in gastric cancer growth, we co-injected HGC-27 cells with GC-MSCs, GCN-MSCs or BM-MSCs into BALB/c nude mice to establish subcutaneous xenograft tumour models. HGC-27 cells alone were used as a control. The growth of xenograft tumours was monitored for 4 weeks, and then, the mice were euthanised and the tumours were removed and weighed. Compared with the control group, tumours in the co-injected groups had remarkably increased in volume (Figure 4A and B) and weight (Figure 4C).

We also determined the levels of GG-miRNAs in xenograft tumour tissues using qRT-PCR. The results showed that the miR-221 levels were significantly increased in tumours from the GC-MSC and BM-MSC groups. The miR-222 level was increased in tumours from the GC-MSCs group but not the other MSC groups. However, the miR-214 levels showed no change in any of the MSC groups (Figure 4D). Moreover, we collected serum from the tumour-bearing mice and determined the circulating levels of miR-214, miR-221 and miR-222. We found that the circulating level of miR-221 was increased in the tumour-bearing groups compared with that in the control group and was highest in the GC-MSC group. The circulating level of miR-214 was only increased in the GC-MSC group, and the circulating levels of miR-222 in the GC-MSC group were similar to those of the GCN-MSC and BM-MSC groups but were markedly higher than that of the HGC-27 group (Figure 4E).

GG-miRNA-221 mediates the effects of GC-MSCs on gastric cancer cells. Given that GC-MSCs significantly promoted gastric cancer cell proliferation and migration and two GG-miRNAs (miR-221 and miR-222) were significantly highly expressed in GCMSCs and gastric cancer cells treated with GC-MSC, we wanted to determine whether GG-miRNAs mediated the function of GC-MSCs. Therefore, we choose miR-221 as a representative of the GG-miRNAs. We introduced a sequence-specific miR-221 inhibitor (anti-miR-221) to repress miR-221 expression. The inhibition efficacy in GC-MSCs was as high as 95\% (Figure 5A). We transfected GC-MSCs with anti-miR-221 or NC oligonucleotides and performed transwell migration and colony forming assays to determine the effects of GC-MSCs on HGC-27 cell migration and proliferation. We found that inhibition of miR-221 in GC-MSCs significantly suppressed the proliferative and migratory abilities of gastric cancer cells (Figure 5B and C). To demonstrate that GC-MSCs regulated miR-221 expression in HGC-27 cells, we transfected HGC-27 cells with anti-miR-221, and cultured the cells 
Table 2. Clinical significances of GG-miRNAs in gastric cancer

\begin{tabular}{|c|c|c|c|c|c|c|c|c|c|}
\hline \multirow[b]{2}{*}{ Factors (no.) } & \multicolumn{3}{|c|}{ miR-214 expression } & \multicolumn{3}{|c|}{ miR-221 expression } & \multicolumn{3}{|c|}{ miR-222 expression } \\
\hline & High (no.) & Low (no.) & $\boldsymbol{P}$-value & High (no.) & Low (no.) & $\boldsymbol{P}$-value & High (no.) & Low (no.) & $P$-value \\
\hline \multicolumn{10}{|l|}{ Gender } \\
\hline $\begin{array}{l}\text { Male (35) } \\
\text { Female (17) }\end{array}$ & $\begin{array}{r}17 \\
9\end{array}$ & $\begin{array}{r}19 \\
7\end{array}$ & 0.768 & $\begin{array}{l}16 \\
10\end{array}$ & $\begin{array}{r}19 \\
7\end{array}$ & 0.375 & $\begin{array}{l}15 \\
11\end{array}$ & $\begin{array}{r}20 \\
6\end{array}$ & 0.139 \\
\hline \multicolumn{10}{|l|}{ Age (years) } \\
\hline $\begin{array}{l}\geqslant 60(27) \\
<60(25)\end{array}$ & $\begin{array}{l}16 \\
10\end{array}$ & $\begin{array}{l}12 \\
14\end{array}$ & 0.165 & $\begin{array}{l}15 \\
11\end{array}$ & $\begin{array}{l}12 \\
14\end{array}$ & 0.405 & $\begin{array}{l}15 \\
11\end{array}$ & $\begin{array}{l}12 \\
14\end{array}$ & 0.405 \\
\hline \multicolumn{10}{|l|}{ Tumour diameter } \\
\hline $\begin{array}{l}\geqslant 5 \mathrm{~cm}(27) \\
<5 \mathrm{~cm}(25)\end{array}$ & $\begin{array}{l}14 \\
12\end{array}$ & $\begin{array}{l}13 \\
13\end{array}$ & 0.555 & $\begin{array}{l}14 \\
12\end{array}$ & $\begin{array}{l}13 \\
13\end{array}$ & 0.555 & $\begin{array}{l}13 \\
13\end{array}$ & $\begin{array}{l}14 \\
12\end{array}$ & 0.982 \\
\hline \multicolumn{10}{|l|}{ Type } \\
\hline $\begin{array}{l}\text { Early (4) } \\
\text { Advance (48) }\end{array}$ & $\begin{array}{r}1 \\
25\end{array}$ & $\begin{array}{r}2 \\
24\end{array}$ & 0.610 & $\begin{array}{r}2 \\
24\end{array}$ & $\begin{array}{r}2 \\
24\end{array}$ & 0.997 & $\begin{array}{r}1 \\
25\end{array}$ & $\begin{array}{r}3 \\
23\end{array}$ & 0.610 \\
\hline \multicolumn{10}{|c|}{ Depth of invasion $(T)$} \\
\hline $\begin{array}{l}\text { T1, T2 (25) } \\
\text { T3, T4 (27) }\end{array}$ & $\begin{array}{r}7 \\
19\end{array}$ & $\begin{array}{l}16 \\
10\end{array}$ & $0.002^{a}$ & $\begin{array}{l}10 \\
16\end{array}$ & $\begin{array}{l}16 \\
10\end{array}$ & 0.096 & $\begin{array}{r}8 \\
18\end{array}$ & $\begin{array}{r}18 \\
8\end{array}$ & $0.006^{\mathrm{a}}$ \\
\hline \multicolumn{10}{|c|}{ Lymph node metastasis (N) } \\
\hline $\begin{array}{l}\text { Negative (N0) (16) } \\
\text { Positive (N1) (20) } \\
\text { Positive (N2) (11) } \\
\text { Positive (N3) (5) }\end{array}$ & $\begin{array}{l}6 \\
8 \\
7 \\
5\end{array}$ & $\begin{array}{r}12 \\
11 \\
2 \\
1\end{array}$ & 0.051 & $\begin{array}{l}4 \\
9 \\
9 \\
4\end{array}$ & $\begin{array}{r}12 \\
11 \\
2 \\
1\end{array}$ & $0.013^{a}$ & $\begin{array}{r}4 \\
10 \\
8 \\
4\end{array}$ & $\begin{array}{r}12 \\
10 \\
3 \\
1\end{array}$ & $0.042^{a}$ \\
\hline \multicolumn{10}{|l|}{ Venous invasion } \\
\hline $\begin{array}{l}\text { Negative (42) } \\
\text { Positive (10) }\end{array}$ & $\begin{array}{r}18 \\
8\end{array}$ & $\begin{array}{r}23 \\
3\end{array}$ & $0.035^{a}$ & $\begin{array}{r}19 \\
7\end{array}$ & $\begin{array}{r}23 \\
3\end{array}$ & 0.159 & $\begin{array}{r}20 \\
6\end{array}$ & $\begin{array}{r}22 \\
4\end{array}$ & 0.482 \\
\hline \multicolumn{10}{|l|}{ TNM stages } \\
\hline $\begin{array}{l}\text { I (14) } \\
\text { II (11) } \\
\text { III (20) } \\
\text { IV (7) }\end{array}$ & $\begin{array}{r}4 \\
4 \\
11 \\
7\end{array}$ & $\begin{array}{r}10 \\
9 \\
6 \\
1\end{array}$ & $0.011^{\mathrm{a}}$ & $\begin{array}{r}4 \\
2 \\
14 \\
6\end{array}$ & $\begin{array}{r}10 \\
9 \\
6 \\
1\end{array}$ & $0.002^{a}$ & $\begin{array}{r}2 \\
4 \\
16 \\
4\end{array}$ & $\begin{array}{r}12 \\
7 \\
4 \\
3\end{array}$ & $0.001^{a}$ \\
\hline
\end{tabular}

in differernt MSC-CM. As shown in Figure 5D and E, miR-221 suppression in HGC-27 cells by anti-miR-221 could be reversed by GC-MSC-CM. These data indicate that GC-MSCs promote gastric cancer progression dependent on GG-miRNAs levels and by relying on the regulation of GG-miRNA expression in gastric cancer cells.

GC-MSC-derived exosomes promote gastric cancer cell proliferation and migration. GC-MSC-CM upregulated the miR-221 expression level in gastric cancer cells, but the precise mechanism is unclear. Exosomes are membrane-derived vesicles that have been recognised as important mediators of intercellular communication because they carry miRNAs that can be transferred to a recipient cell via fusion of the exosome with the target cell membrane. To evaluate whether exosomes from GC-MSC-CM (GC-MSC-ex) could be delivered to gastric cancer cells and promote cell proliferation and migration, we successfully isolated $40-100-\mathrm{nm}$ particles that were exosomal marker CD63-positive from GC-MSC-CM and GCN-MSC-CM, respectively (Figure 6A). To investigate the internalisation of exosomes by gastric cancer cells, we labelled the exosomes with CM-Dil. As shown in Figure 6B, GC-MSC-ex and GCN-MSC-CM-derived exosomes (GCNMSC-ex) were internalised and accumulated in HGC-27 cells after incubation for $4 \mathrm{~h}$, whereas the exosome control showed a minimal effect. Colony formation and transwell assays showed that GC-MSC-ex promoted HGC-27 cell proliferation and migration more obviously than GCN-MSC-ex (Figure 6C).

GC-MSC-exosomes alter GG-miRNA expression in gastric cancer cells. The above results showed that GG-miR-221 was an important communicational signal between GC-MSC and gastric cancer cells and that exosomes could be delivered from GC-MSCs to gastric cancer cells. We wanted to determine whether miR-221 is carried in GC-MSC-ex and affects the corresponding miRNAs expression level in gastric cancer cells. Therefore, we performed qRT-PCR to determine the miR-221 expression levels in GC-MSC-ex, GCN-MSC-ex and exosome-treated HGC-27 cells. The results revealed that miR-221 was signifiantly highly expressed in exosomes secreted by GC-MSCs than those secreted by GCN-MSCs (Figure 6D), and GC-MSC-ex significantly induced 


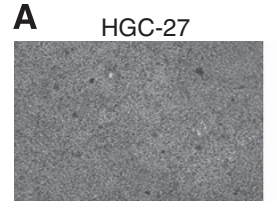

GCN-MSC

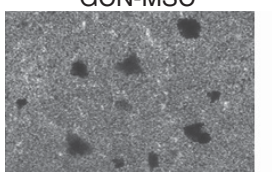

B

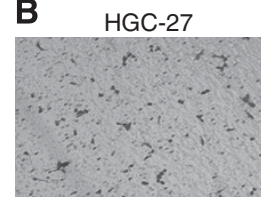

GCN-MSC

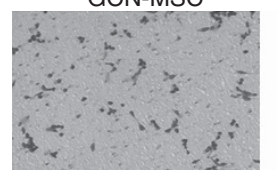

GC-MSC

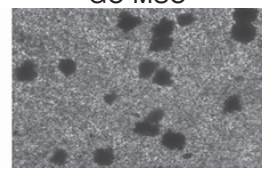

BM-MSC

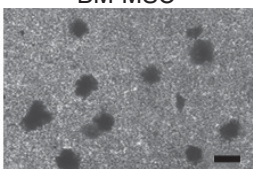

GC-MSC

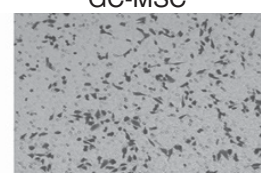

BM-MSC

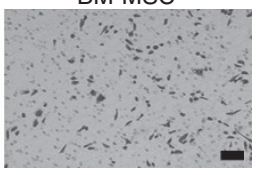

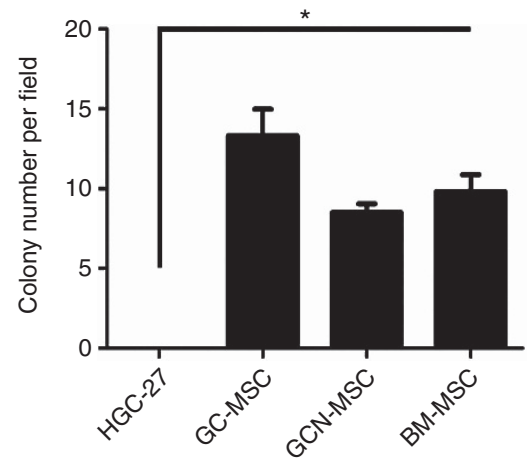

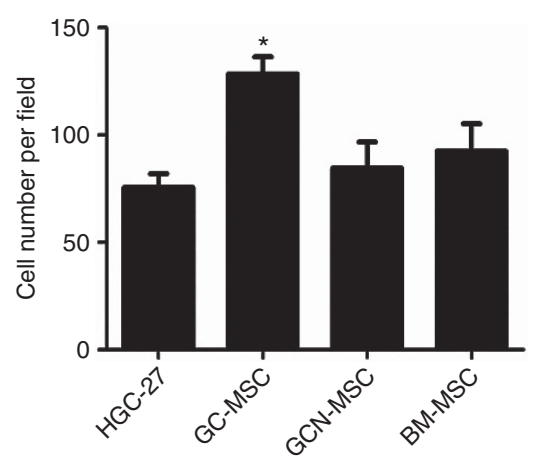

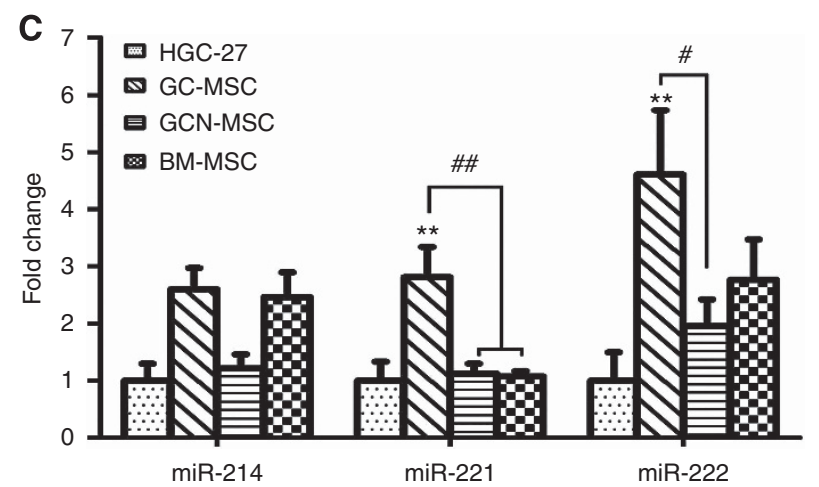

Figure 3. GC-MSCs promote gastric cancer cell proliferation, migration and GG-miRNA expression in vitro. (A) The soft agar colony formation assay of gastric cancer HGC-27 cells treated with GC-MSCs, GCN-MSCs or BM-MSCs. HGC-27 cells alone were used as a control. Magnification, $\times$ 40. Scale bar $=200 \mu \mathrm{m}$. (B) The transwell migration assay of HGC-27 cells treated with GC-MSCs, GCN-MSCs or BM-MSCs. Magnification, $\times$ 100. Scale bar $=50 \mu \mathrm{m}$. ${ }^{*}>0.05$ vs HGC-27. (C) GG-miRNA levels in HGC-27 cells treated with MSC-CM. HGC-27 cells cultured in normal growth medium were used as a control. Data are shown as the fold change of the miRNA levels relative to those in the HGC-27 group, which were set to $1 .{ }^{\star \star} P<0.01$ vs HGC-27 group; ${ }^{\#} P<0.05 ;{ }^{\# \#} P<0.01$.

miR-221 expression in HGC-27 cells (Figure 6E). To further demonstrate that GC-MSCs regulate miR-221 expression in HGC-27 cells via exosomes, we transfected HGC-27 cells with anti-miR-221 and treated them with GC-MSC-derived exosomes. As shown in Figure 6F, miR-221 suppression in HGC-27 cells by anti-miR-221 could be reversed by GC-MSC-ex, similar to GC-MSC-CM. These data indicate that GC-MSCs alter the GG-miR-221 expression level in gastric cancer cells via delivering exosomal miRNAs to target cells.

\section{DISCUSSION}

The tumour-stroma interaction is critical for carcinogenesis and cancer progression (Pietras and Ostman, 2010). In our previous studies, we successfully isolated two distinct gastric cancerassociated MSCs, GC-MSCs and GCN-MSCs, from gastric cancer tissues and their adjacent non-cancerous tissues. The studies from others demonstrate that cancer-associated MSCs are also present in breast cancer, ovarian carcinoma and hepatocellular carcinoma (McLean et al, 2011; Yan et al, 2012, 2013), which indicate that cancer-associated MSCs are important members of the tumour microenvironment and may have essential roles in the development and progression of cancer. Accumulating evidence suggests that gastric cancer cells have different miRNA signatures and that their levels are associated with the malignancy of gastric cancer (Wu et al, 2010). However, the expression and role of miRNAs in cancer-associated MSCs are obscure thus far.

Although the presence of GC-MSCs and GCN-MSCs in gastric cancer has been demonstrated, the effects of these MSCs on gastric cancer cells are not well understood. We demonstrated that GC-MSCs, as tumour-supporting stromal cells, prompt the growth and migration of gastric cancer cells in vitro. An in vivo xenograft tumour model also demonstrated that GC-MSCs could induce aggressive tumour growth in nude mice. These results were consistent with those from previous studies showing that tumourassociated stromal cells from breast cancer, ovarian carcinoma and 

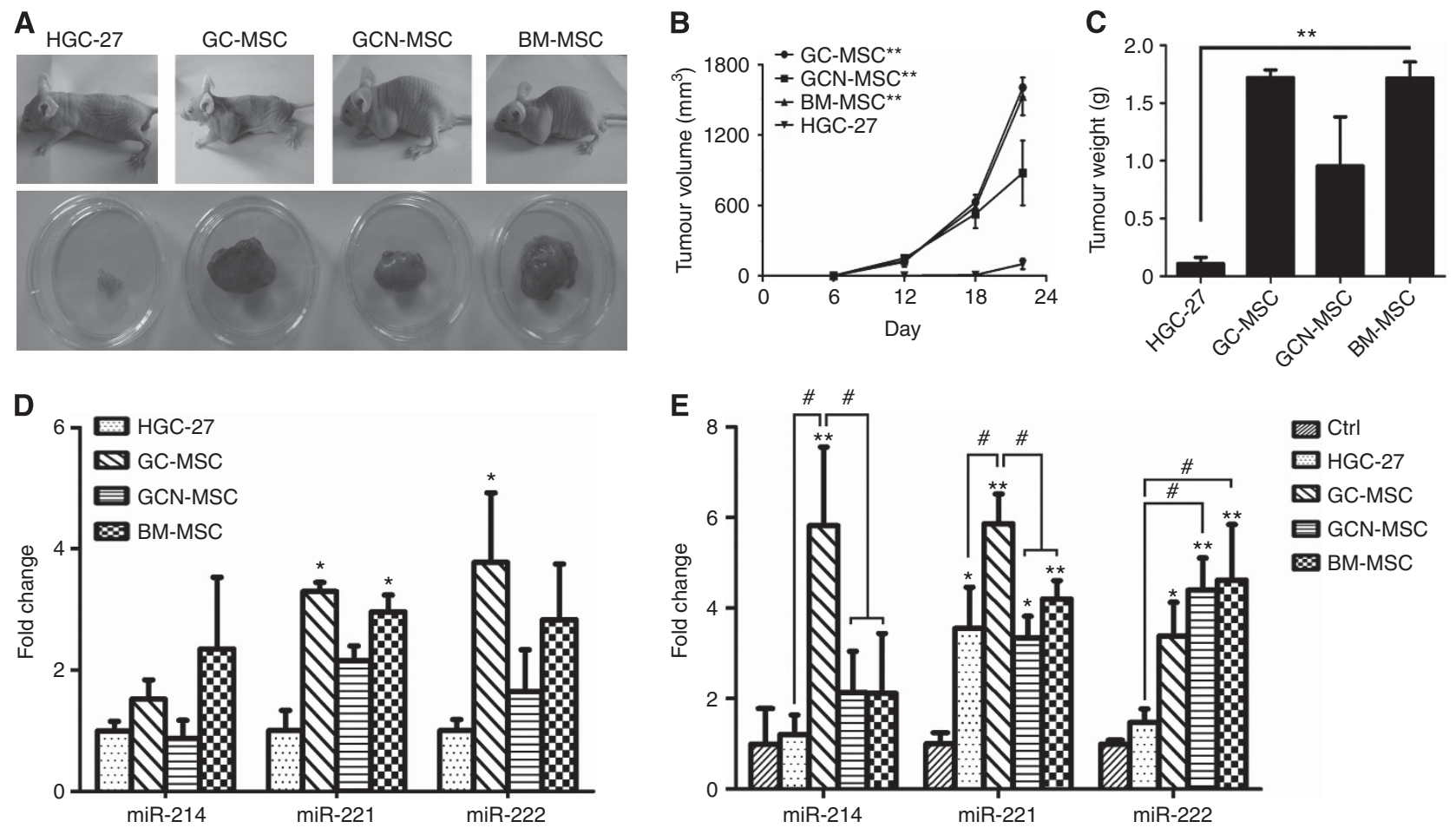

Figure 4. GC-MSCs promote gastric cancer growth and GG-miRNA expression in vivo. (A) HGC-27 cells and GC-MSCs, GCN-MSCs or BM-MSCs were subcutaneously co-injected into the flanks of BALB/c nude mice. The upper image shows tumour growth in a representative nude mouse, and the lower image shows tumour tissues that were removed from the same nude mouse. (B) Tumour volumes were measured at the indicated time points. (C) Tumour weights were measured after the mouse was euthanised. The data were expressed as mean $\pm s . d$. ( $n=6$ per group). ${ }^{\star \star} P<0.01$ vs HGC-27 alone. (D) GG-miRNA expression in xenograft tumours. ${ }^{*} P<0.05$ vs HGC-27 alone. (E) Serum levels of GG-miRNAs in mice injected with HGC-27 cells alone or mixed with MSCs. The control represents the levels of the miRNAs in the serum of normal mice. Data are shown as the fold change of miRNA levels relative to the control, which was set to $1 .{ }^{\star} P<0.05$ vs control; ${ }^{\star \star} P<0.01$ vs control; ${ }^{\#} P<0.05$.

hepatocellular carcinoma could provide a favourable microenvironment for cancer cell growth (McLean et al, 2011; Yan et al, 2012, 2013).

In this study, we also identified the miRNA profile of GC-MSCs and their matched cancer tissues using a microRNA microarray. Interestingly, we found overlapping miRNAs in the GC-MSC and cancer-tissue miRNA profiles. Among these miRNAs, three miRNAs (miR-214, miR-221 and miR-222) were validated and named GG-miRNAs. Combined with clinicopathological characteristics, we found that GG-miRNA levels in cancer tissues were higher than those in non-cancerous tissues. Moreover, their levels were significantly correlated with cancer pathological conditions. Upregulation of miR-214 is associated with an unfavourable outcome of gastric cancer (Ueda et al, 2010). High expression of miR-221 showed a significant correlation with advanced tumournode-metastasis stage, local invasion and lymphatic metastasis (Liu et al, 2012). Notably, these previous findings were established based on analysis of miRNAs using qRT-PCR in a large number of gastric cancer tissues. However, we detected these miRNAs in a smaller sample size. These data indicate that the aberrant expression of miRNAs that overlap between GC-MSCs and gastric cancer tissues may be useful when searching for a more sensitive biomarker for gastric cancer diagnosis and clinicopathological progression monitoring.

Previously, the expression and role of miRNAs were only studied in cancer cells and tissues and not tumour stromal cells. Zhao et al (2012) suggested that breast cancer-derived cancerassociated fibroblasts (CAFs) and normal fibroblasts have distinct miRNA expression patterns. Musumeci et al (2011) found that downregulation of miR-15 and miR-16 in CAFs promoted prostate cancer growth and progression. We used an miRNA inhibitor of
GG-miR-221 to reduce its expression levels in GC-MSCs, and we found that downregulation of miR-221 could significantly impair the tumour-promoting effects of GC-MSCs. These data indicate that the GG-miRNAs identified in our study are important for GC-MSCs to sustain their tumour-supporting roles, and they may be explored as therapeutic targets for gastric cancer.

It is known that cancer tissue contains two parts: tumour stroma and cancer cells. The tumour stroma consists of the extracellular matrix and various mesenchymal cell types. Therefore, the miRNAs expression profile that was identified in the gastric cancer tissue cannot be attributed to a specific cell type. The levels of GG-miRNA expression in gastric cancer cells are not clear. Fortunately, we found that GG-miRNA levels were upregulated in GC-MSC and gastric cancer cells that were treated with a conditioned medium from GC-MSCs or indirectly co-cultured with GC-MSCs in an in vitro study. MiR-221 repression by an miRNA inhibitor in gastric cancer cells could be reversed by GC-MSC-conditioned medium, suggesting that these GG-miRNAs may also be involved in the cross-talk between GC-MSCs and gastric cancer cells through paracrine secretion.

Recently, the importance of exosomes as paracrine mediators has increasingly drawn attention (Nazarenko et al, 2013). Moreover, miRNAs were enriched in exosomes that could be transferred between cells (Zomer et al, 2010). On the basis of these findings and the above results, we hypothesised that GG-miRNAs might be packaged into GC-MSC-secreted exosomes, delivered into gastric cancer cells and mediate GC-MSC-promoting gastric cancer progression. To confirm this hypothesis, we isolated exosomes from GC-MSC-CM and GCN-MSC-CM and used those exosomes instead of the MSC-CM to observe their effect on gastric cancer cells. Surprisingly, GC-MSC-derived exosomes could be instantly 


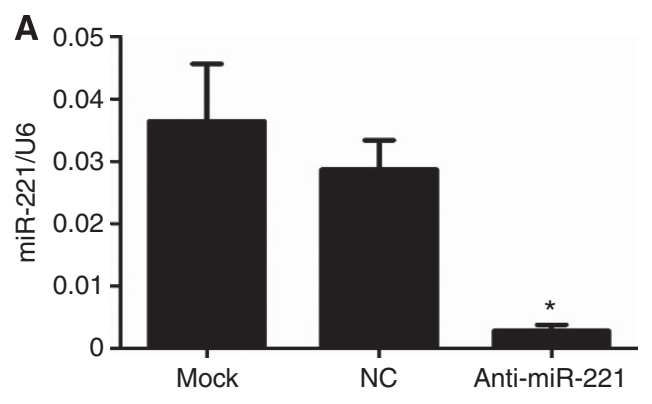

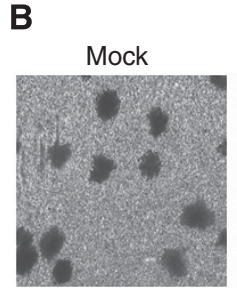
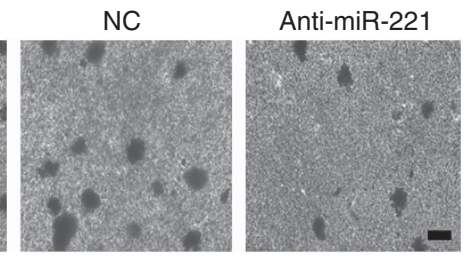

C
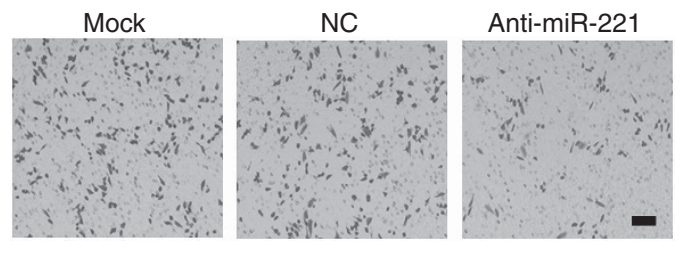
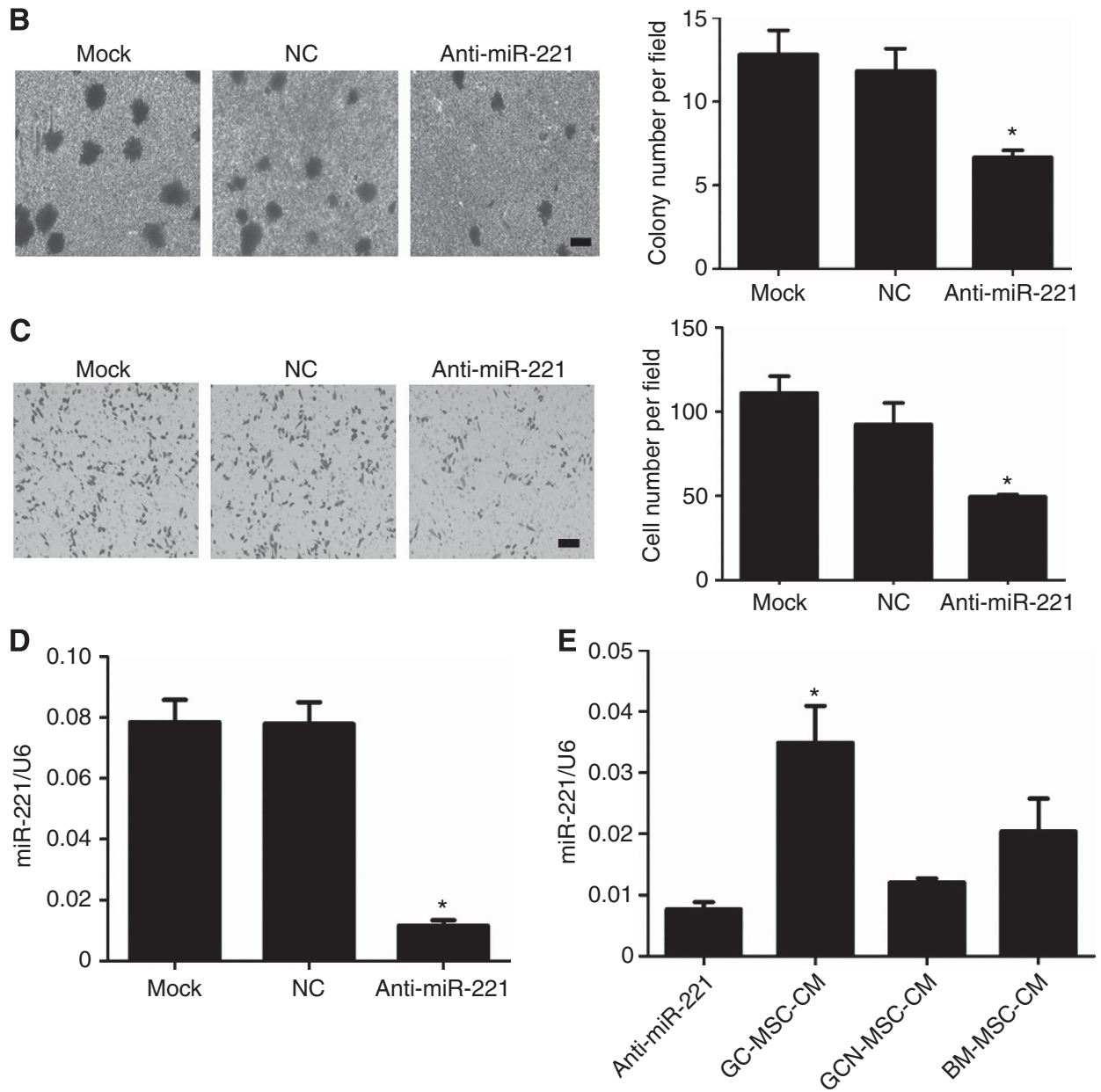

Figure 5. GG-miR-221 mediates the promoting role of GC-MSCs towards gastric cancer cells. (A) Quantitative RT-PCR analysis of miR-221 levels $48 \mathrm{~h}$ after GC-MSCs were transfected with an miR-221 inhibitor (anti-miR-221) or NC oligonucleotides. (B) The soft agar colony formation assay of HGC-27 cells. GC-MSCs transfected with anti-miR-221 or NC were seeded at the bottom of the wells. Colonies in the top agar were photographed. Magnification, $\times 40$. Scale bar $=200 \mu \mathrm{m}$. ${ }^{\star} P<0.05$ vs mock. (C) The transwell migration assay of HGC-27 cells treated with GC-MSCs. GC-MSCs transfected with anti-miR-221 or NC were seeded in the lower chamber, and HGC-27 cells were seeded in the upper chamber. Magnification, $\times 100$. Scale bar $=50 \mu \mathrm{m} .{ }^{\star} P<0.05$ vs mock. (D) Quantitative RT-PCR analysis of miR-221 levels $48 \mathrm{~h}$ after HGC-27 cells were transfected with anti-miR-221 or NC. (E) HGC-27 cells transfected with anti-miR-221 were cultured in different CMs from MSCs for 48 h, and a qRT-PCR assay for miR-221 levels in HGC-27 cells was performed. ${ }^{\star} P<0.05$ vs anti-miR-221 group.

internalised by gastric cancer cells and significantly promoted cell proliferation and migration. MicroRNA analysis demonstrated that higher contents of miR-221 existed in GC-MSC-ex, and that the status of miR-221 suppression could be induced and reversed by an miRNA inhibitor in gastric cancer cells.

An increasing number of studies have demonstrated that miR-221 is frequently overexpressed in the majority of human epithelial tumours, including gastric cancer (Kim et al, 2009; Chun-Zhi et al, 2010). MiR-221 functions as an oncomiRNA by downregulating several identified tumour suppressor target genes: the cyclin-dependent kinase inhibitors CDKN1B/p27 and
CDKN1C/p57, the pro-apoptotic factors BMF and BBC3/PUMA, the PI3K/AKT pathway inhibitor PTEN, the cell adhesion regulator $\operatorname{PTP} \mu$ and the metallopeptidase inhibitor TIMP3 (Garofalo et al, 2012). Recently, Lupini et al performed gene expression profile analysis of an miR-221-tranfected cell line and identified 602 new gene targets that were prominently involved in cell proliferation and apoptosis (Lupini et al, 2013). On the basis of this information, the induction of miR-221 expression in gastric cancer cells is important for the effects of GC-MSCs on gastric cancer. The induction of GG-miRNAs in gastric cancer cells by GC-MSCs likely reduces the expression of these potential tumour 
A

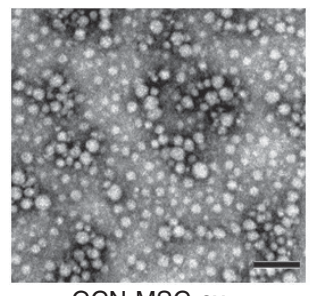

GCN-MSC-ex

B

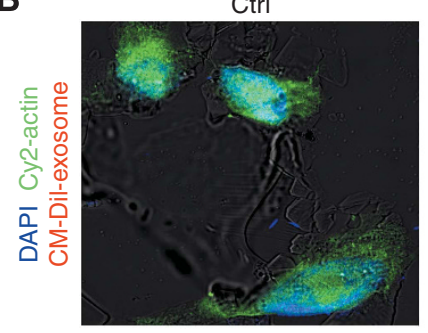

C

PBS

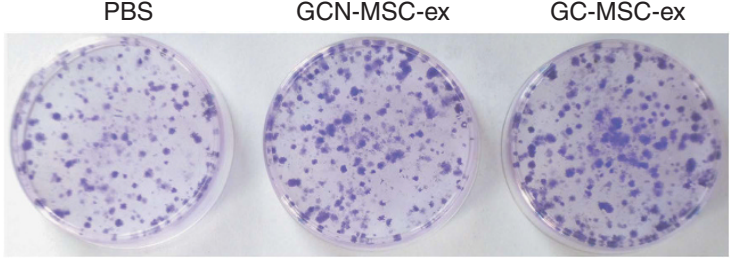

PBS
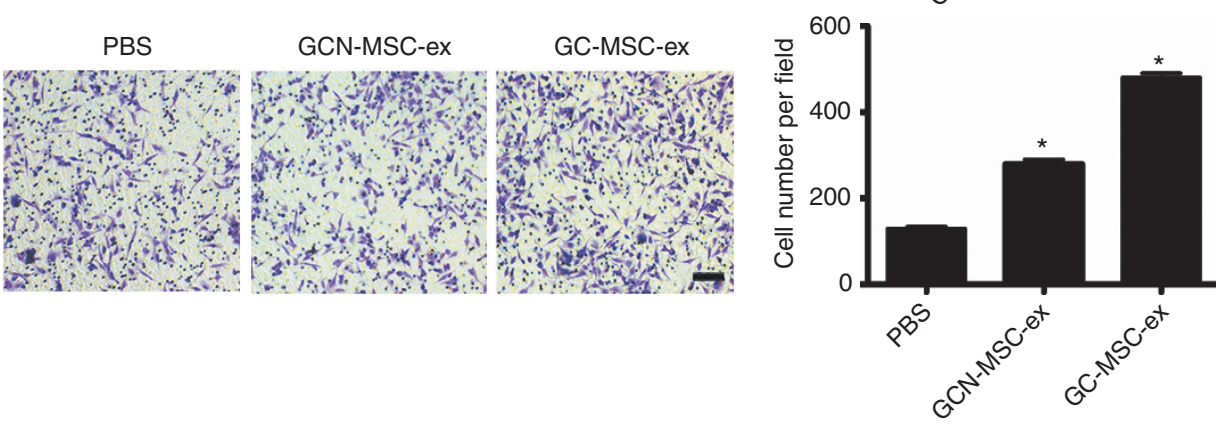

D
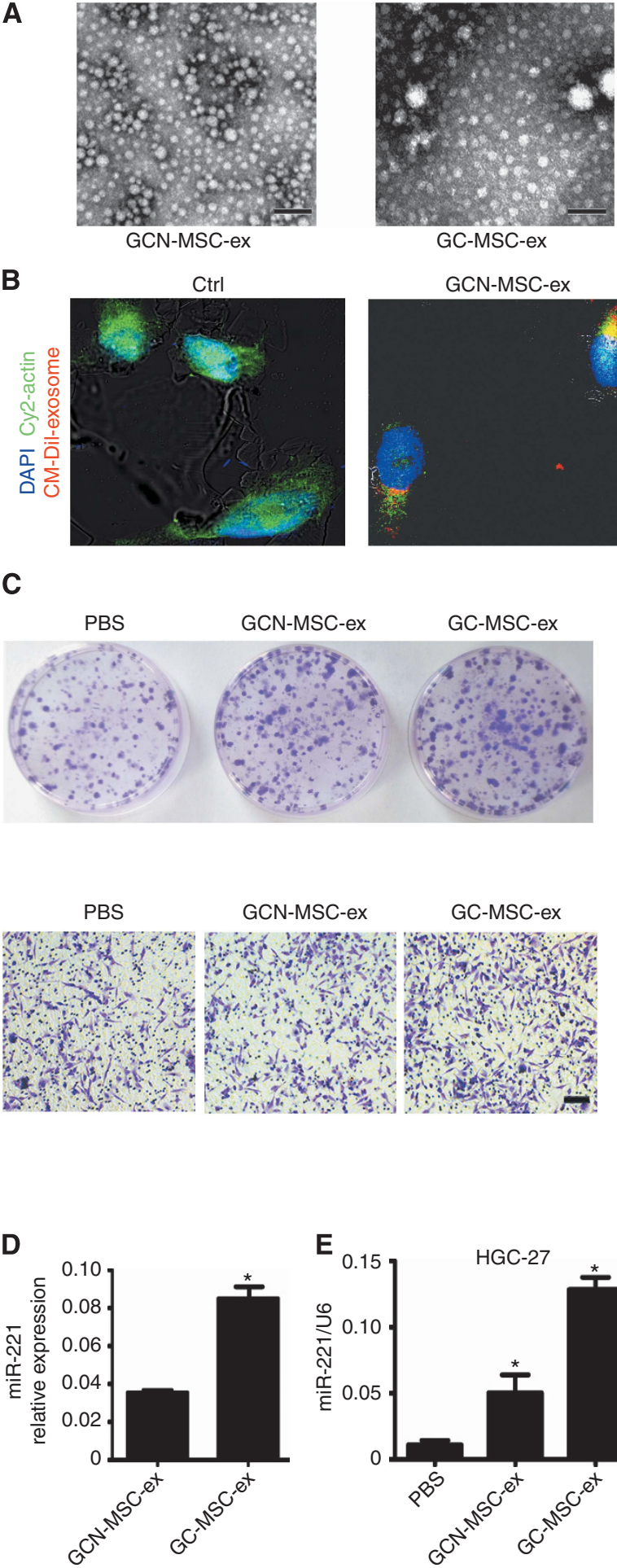

GC-MSC-ex
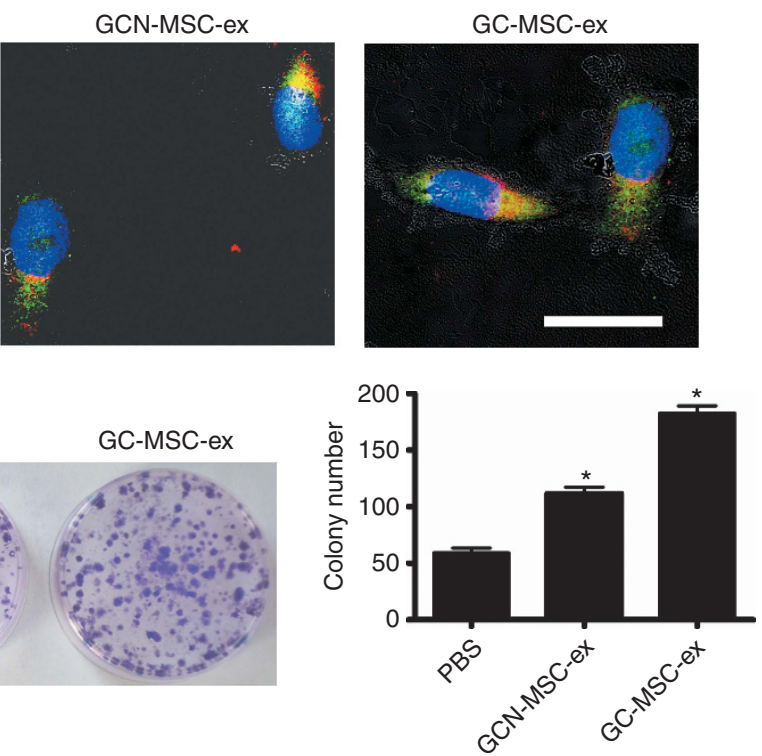

E

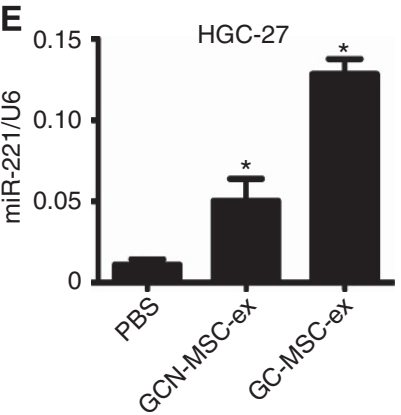

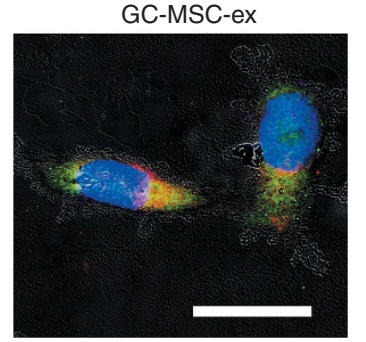

CD63<smiles>C=COC(=O)O</smiles>
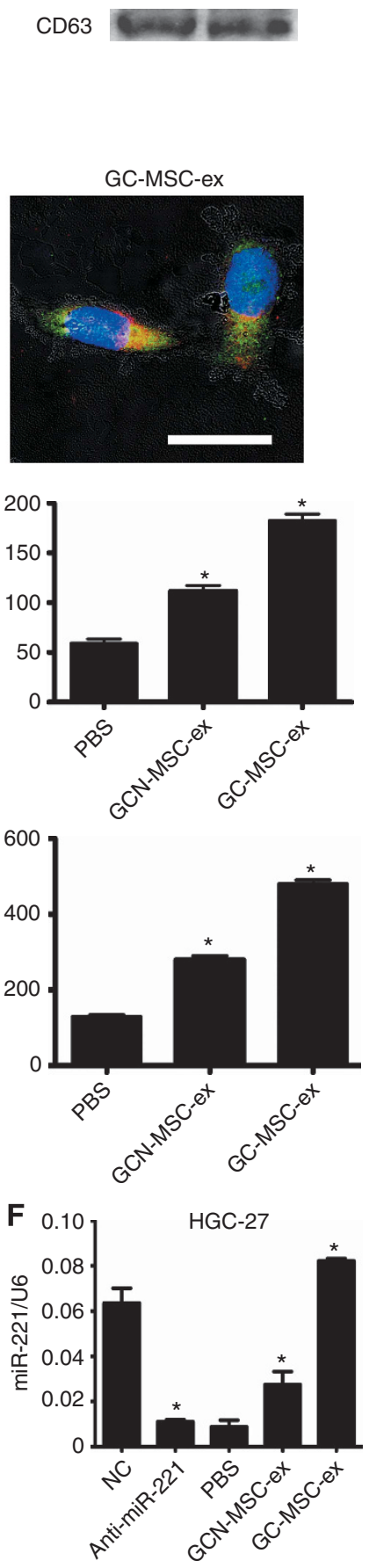

Figure 6. GC-MSC-exosomes promote cells proliferation and migration via delivering exosomal miR-221 to gastric cancer cells.

(A) Representative transmission electron micrographs of purified GCN-MSC- and GC-MSC-derived exosomes (GCN-MSC-ex, GC-MSC-ex), which showed a spheroid shape. The scale bar represents $100 \mathrm{~nm}$. Western blotting results indicated the positive expression of the CD63 protein in exosomes. (B) Exosomes were internalised by gastric cancer cells. Exosomes labelled with CM-Dil (red) were added into HGC-27 cells and incubated for $4 \mathrm{~h}$. The effluent from a filtered suspension of CM-Dil-labelled exosome and the CM-Dil-labelled withdrawn exosome fractions were used as controls. Cells were fixed and stained for cytoplasm (cy2-actin, green) and nuclei (DAPI, blue). Magnification, $\times 400$. Scale bar $=25 \mu$ m. (C) GC-MSC-exosomes promoted HGC-27 proliferation and migration. Colony formation and transwell migration assay of HGC-27 cells treated with GC-MSC-ex, GCN-MSC-ex or PBS. Colonies and migrated cells on the lower layer were stained and photographed. Magnification, $\times 100$. Scale bar $=50 \mu \mathrm{m}$. ${ }^{\star} P<0.05$ (GCN-MSC-ex vs PBS, GC-MSC-ex vs GCN-MSC-ex). (D-F) GC-MSCs alter the miR-221 level in gastric cancer cells via delivering exosomal miR-221. (D) Quantitative RT-PCR analysis of miR-221 levels in GC-MSC-ex and GCN-MSC-ex. * $P<0.05$ for GC-MSC-ex vs GCN-MSC-ex. (E) Quantitative RT-PCR of miR-221 levels in HGC-27 cells treated with MSC-derived exosomes. *P<0.05 (GCN-MSC-ex vs PBS, GC-MSC-ex vs GCN-MSC-ex). (F) HGC-27 cells transfected with anti-miR-221 were treated with different exosomes from MSCs for 48 h. The miR221 levels in HGC-27 cells were determined using qRT-PCR. *P<0.05 (NC vs anti-miR-221, GCN-MSC-ex vs PBS, GC-MSC-ex vs GCN-MSC-ex). 
suppressor genes, which leads to an increase in gastric cancer cell proliferation and migration. These data indicate that exosomal miRNA delivery is a critical mechanism for GC-MSCs that act on gastric cancer cells. Future work is required to explore more novel GG-miRNAs and other molecules for gastric cancer diagnosis and to fully elucidate the role and mechanism that is involved in the interaction between GC-MSCs and gastric cancer cells.

In conclusion, we demonstrate in this study that gastric cancerassociated MSCs exhibit aberrant miRNA expression patterns that are shared by MSC-derived gastric cancers and that GG-miRNAs are critical mediators of the role of GC-MSCs in gastric cancer. Our findings suggest a new mechanism for the MSCgastric cancer cell interaction and provide new biomarkers for gastric cancer diagnosis and prognosis.

\section{ACKNOWLEDGEMENTS}

This work was supported by the Major Research Plan of the National Natural Science Foundation of China (Grant No. 91129718), the National Natural Science Foundation of China (Grant No. 81071421, 81302119), Jiangsu Province's Project of Scientific and Technological Innovation and Achievements Transformation (Grant No. BL2012055), Jiangsu Province's Outstanding Medical Academic Leader and Sci-tech Innovation Team Program (Grant No. LJ201117), the Natural Science Foundation of the Jiangsu Province (Grant No. BK2012709, BK20130540), Doctoral Program Foundation of State Education Ministry (Grant No. 20113227110011), Jiangsu Province for Natural Scicence Research in Colleges and Universities (13KJB320001) and the Scientific Research Foundation of Jiangsu University for Senior Professional Talents (13JDG088).

\section{REFERENCES}

Azmi AS, Bao B, Sarkar FH (2013) Exosomes in cancer development, metastasis, and drug resistance: a comprehensive review. Cancer Metastasis Rev 32(3-4): 623-642.

Bergfeld SA, DeClerck YA (2010) Bone marrow-derived mesenchymal stem cells and the tumor microenvironment. Cancer Metastasis Rev 29: 249-261.

Calin GA, Croce CM (2006) MicroRNA signatures in human cancers. Nat Rev Cancer 6: 857-866.

Cao H, Xu W, Qian H, Zhu W, Yan Y, Zhou H, Zhang X, Xu X, Li J, Chen Z (2009) Mesenchymal stem cell-like cells derived from human gastric cancer tissues. Cancer Lett 274: 61-71.

Garofalo M, Quintavalle C, Romano G, Croce CM, Condorelli G (2012) miR221/222 in cancer: their role in tumor progression and response to therapy. Curr Mol Med 12: 27-33.

Cho JA, Park H, Lim EH, Kim KH, Choi JS, Lee JH, Shin JW, Lee KW (2011) Exosomes from ovarian cancer cells induce adipose tissue-derived mesenchymal stem cells to acquire the physical and functional characteristics of tumor-supporting myofibroblasts. Gynecol Oncol 123: 379-386.

Cho JA, Park H, Lim EH, Lee KW (2012) Exosomes from breast cancer cells can convert adipose tissue-derived mesenchymal stem cells into myofibroblast-like cells. Int J Oncol 40: 130-138.

Chun-Zhi Z, Lei H, An-Ling Z, Yan-Chao F, Xiao Y, Guang-Xiu W, Zhi-Fan J, Pei-Yu P, Qing-Yu Z, Chun-Sheng K (2010) MicroRNA-221 and microRNA-222 regulate gastric carcinoma cell proliferation and radioresistance by targeting PTEN. BMC Cancer 10: 367.

Ciesla M, Skrzypek K, Kozakowska M, Loboda A, Jozkowicz A, Dulak J (2011) MicroRNAs as biomarkers of disease onset. Anal Bioanal Chem 401: 2051-2061.

Ding YB, Xia TS, Wu JD, Chen GY, Wang S, Xia JG (2012) Surgical outcomes for gastric cancer of a single institute in southeast China. Am J Surg 203: $217-221$.
Fang H, Declerck YA (2013) Targeting the tumor microenvironment: from understanding pathways to effective clinical trials. Cancer Res 73: 4965-4977.

Gu J, Qian H, Shen L, Zhang X, Zhu W, Huang L, Yan Y, Mao F, Zhao C, Shi Y, Xu W (2012) Gastric cancer exosomes trigger differentiation of umbilical cord derived mesenchymal stem cells to carcinoma-associated fibroblasts through TGF-beta/Smad pathway. PLoS One 7: e52465.

Hanahan D, Coussens LM (2012) Accessories to the crime: functions of cells recruited to the tumor microenvironment. Cancer Cell 21: 309-322.

Hanahan D, Weinberg RA (2011) Hallmarks of cancer: the next generation. Cell 144: 646-674.

Horimoto Y, Polanska UM, Takahashi Y, Orimo A (2012) Emerging roles of the tumor-associated stroma in promoting tumor metastasis. Cell Adh Migr 6: 193-202.

Jemal A, Bray F, Center MM, Ferlay J, Ward E, Forman D (2011) Global cancer statistics. CA Cancer J Clin 61: 69-90.

Kahlert C, Kalluri R (2013) Exosomes in tumor microenvironment influence cancer progression and metastasis. J Mol Med (Berl) 91: 431-437.

Karnoub AE, Dash AB, Vo AP, Sullivan A, Brooks MW, Bell GW, Richardson AL, Polyak K, Tubo R, Weinberg RA (2007) Mesenchymal stem cells within tumour stroma promote breast cancer metastasis. Nature 449: 557-563.

Kim YK, Yu J, Han TS, Park SY, Namkoong B, Kim DH, Hur K, Yoo MW, Lee HJ, Yang HK, Kim VN (2009) Functional links between clustered microRNAs: suppression of cell-cycle inhibitors by microRNA clusters in gastric cancer. Nucleic Acids Res 37: 1672-1681.

Li X, Zhang Y, Ding J, Wu K, Fan D (2010) Survival prediction of gastric cancer by a seven-microRNA signature. Gut 59: 579-585.

Liu K, Li G, Fan C, Diao Y, Wu B, Li J (2012) Increased Expression of MicroRNA-221 in gastric cancer and its clinical significance. J Int Med Res 40: 467-474.

Liu R, Zhang C, Hu Z, Li G, Wang C, Yang C, Huang D, Chen X, Zhang H, Zhuang R, Deng T, Liu H, Yin J, Wang S, Zen K, Ba Y, Zhang CY (2011) A five-microRNA signature identified from genome-wide serum microRNA expression profiling serves as a fingerprint for gastric cancer diagnosis. Eur J Cancer 47: 784-791.

Lupini L, Bassi C, Ferracin M, Bartonicek N, D’Abundo L, Zagatti B, Callegari E, Musa G, Moshiri F, Gramantieri L, Corrales FJ, Enright AJ, Sabbioni S, Negrini M (2013) miR-221 affects multiple cancer pathways by modulating the level of hundreds messenger RNAs. Front Genet 4: 64 .

McLean K, Gong Y, Choi Y, Deng N, Yang K, Bai S, Cabrera L, Keller E, McCauley L, Cho KR, Buckanovich RJ (2011) Human ovarian carcinoma-associated mesenchymal stem cells regulate cancer stem cells and tumorigenesis via altered BMP production. J Clin Invest 121: 3206-3219.

Musumeci M, Coppola V, Addario A, Patrizii M, Maugeri-Sacca M, Memeo L, Colarossi C, Francescangeli F, Biffoni M, Collura D, Giacobbe A, D’Urso L, Falchi M, Venneri MA, Muto G, De Maria R, Bonci D (2011) Control of tumor and microenvironment cross-talk by miR-15a and miR-16 in prostate cancer. Oncogene 30: 4231-4242.

Nazarenko I, Rupp AK, Altevogt P (2013) Exosomes as a potential tool for a specific delivery of functional molecules. Methods Mol Biol 1049: 495-511.

Pietras K, Ostman A (2010) Hallmarks of cancer: interactions with the tumor stroma. Exp Cell Res 316: 1324-1331.

Roccaro AM, Sacco A, Maiso P, Azab AK, Tai YT, Reagan M, Azab F, Flores LM, Campigotto F, Weller E, Anderson KC, Scadden DT, Ghobrial IM (2013) BM mesenchymal stromal cell-derived exosomes facilitate multiple myeloma progression. J Clin Invest 123: 1542-1555.

Roorda BD, ter Elst A, Kamps WA, de Bont ES (2009) Bone marrow-derived cells and tumor growth: contribution of bone marrow-derived cells to tumor micro-environments with special focus on mesenchymal stem cells. Crit Rev Oncol Hematol 69: 187-198.

Tsujiura M, Ichikawa D, Komatsu S, Shiozaki A, Takeshita H, Kosuga T, Konishi H, Morimura R, Deguchi K, Fujiwara H, Okamoto K, Otsuji E (2010) Circulating microRNAs in plasma of patients with gastric cancers. Br J Cancer 102: 1174-1179.

Ueda T, Volinia S, Okumura H, Shimizu M, Taccioli C, Rossi S, Alder H, Liu CG, Oue N, Yasui W, Yoshida K, Sasaki H, Nomura S, Seto Y, Kaminishi M, Calin GA, Croce CM (2010) Relation between microRNA expression and progression and prognosis of gastric cancer: a microRNA expression analysis. Lancet Oncol 11: 136-146.

Valadi H, Ekstrom K, Bossios A, Sjostrand M, Lee JJ, Lotvall JO (2007) Exosome-mediated transfer of mRNAs and microRNAs is a novel mechanism of genetic exchange between cells. Nat Cell Biol 9: 654-659. 
Webber J, Steadman R, Mason MD, Tabi Z, Clayton A (2010) Cancer exosomes trigger fibroblast to myofibroblast differentiation. Cancer Res 70: 9621-9630.

Wu WK, Lee CW, Cho CH, Fan D, Wu K, Yu J, Sung JJ (2010) MicroRNA dysregulation in gastric cancer: a new player enters the game. Oncogene 29: $5761-5771$.

Xu X, Zhang X, Wang S, Qian H, Zhu W, Cao H, Wang M, Chen Y, Xu W (2011) Isolation and comparison of mesenchymal stem-like cells from human gastric cancer and adjacent non-cancerous tissues. J Cancer Res Clin Oncol 137: 495-504.

Yan XL, Fu CJ, Chen L, Qin JH, Zeng Q, Yuan HF, Nan X, Chen HX, Zhou JN, Lin YL, Zhang XM, Yu CZ, Yue W, Pei XT (2012) Mesenchymal stem cells from primary breast cancer tissue promote cancer proliferation and enhance mammosphere formation partially via EGF/EGFR/Akt pathway. Breast Cancer Res Treat 132: 153-164.

Yan XL, Jia YL, Chen L, Zeng Q, Zhou JN, Fu CJ, Chen HX, Yuan HF, Li ZW, Shi L, Xu YC, Wang JX, Zhang XM, He LJ, Zhai C, Yue W, Pei XT (2013) Hepatocellular carcinoma-associated mesenchymal stem cells promote hepatocarcinoma progression: role of the S100A4-miR155SOCS1-MMP9 axis. Hepatology 57: 2274-2286.

Yang X, Hou J, Han Z, Wang Y, Hao C, Wei L, Shi Y (2013) One cell, multiple roles: contribution of mesenchymal stem cells to tumor development in tumor microenvironment. Cell Biosci 3: 5.

Zhao L, Sun Y, Hou Y, Peng Q, Wang L, Luo H, Tang X, Zeng Z, Liu M (2012) MiRNA expression analysis of cancer-associated fibroblasts and normal fibroblasts in breast cancer. Int J Biochem Cell Biol 44: 2051-2059.

Zomer A, Vendrig T, Hopmans ES, van Eijndhoven M, Middeldorp JM, Pegtel DM (2010) Exosomes: fit to deliver small RNA. Commun Integr Biol 3: 447-450.

This work is published under the standard license to publish agreement. After 12 months the work will become freely available and the license terms will switch to a Creative Commons AttributionNonCommercial-Share Alike 3.0 Unported License. 